\title{
A MATEMÁTICA NO PIBID INTERDISCIPLINAR: EDUCAÇÃO INCLUSIVA
}

\section{THE MATHEMATICS IN THE PIBID INTERDISCIPLINARY: INCLUSIVE EDUCATION}

DOI: http://dx.doi.org/10.5965/1984317816012020100

\author{
Jurema Lindote Botelho Peixoto \\ Universidade Estadual de Santa Cruz \\ jurema@uesc.br \\ Cristiane Andrade Fernandes \\ Centro Educativo Fé e Alegria \\ crisuesc@gmail.com \\ Wolney Gomes Almeida \\ Universidade Estadual de Santa Cruz \\ wolney_22@yahoo.com.br
}

\begin{abstract}
RESUMO
A inclusão de estudantes com deficiência na escola básica é uma realidade que desafia a escola e seus professores. Os cursos de Licenciatura necessitam abordar as especificidades desses estudantes no processo de ensino e aprendizagem. Neste artigo, é apresentada a organização do trabalho pedagógico do subprojeto Programa Institucional de Bolsa de Iniciação à Docência (Pibid) Interdisciplinar, na área de Matemática, no contexto da educação inclusiva, no período de 2016 a 2018. A coordenação das três áreas envolvidas, Matemática, Letras e Pedagogia, apoiaram-se na abordagem da investigação-ação para o desenvolvimento das seguintes atividades: grupo de estudo, planejamento pedagógico, intervenção na escola básica e sistematização das experiências. O planejamento da intervenção foi baseado no Desenho Universal para a aprendizagem e em Atividades Orientadoras de Ensino. As ações proporcionaram a reflexão/problematização sobre os aportes da educação especial na perspectiva inclusiva, ressaltando a importância de (re)conhecer as potencialidades dos diversos estudantes na escola básica. Destaca-se, ainda, a importância da interação da Matemática com outras áreas de conhecimento para o planejamento e enfrentamento da realidade no contexto inclusivo.
\end{abstract}

Palavras-chave: PIBID Interdisciplinar. Educação Inclusiva. Matemática. Formação de professores.

\section{ABSTRACT}

The inclusion of students with disabilities in elementary school is a reality that challenges the school and its teachers. Undergraduate courses need to address the specificities of these students in the teaching and learning processes. This paper aims to present the organization of the pedagogical work of the PIBID (Institutional Program for Teaching Initiation Scholarship) -Interdisciplinary subproject in the area of Mathematics in the context of inclusive education from 2016 to 2018. The coordination of the three areas involved, Mathematics, Portuguese Language/ Literature and Pedagogy, was based on the researchaction approach for the development of the following actions: study group, pedagogical planning, intervention in elementary school and systematization of experiences. The planning of the intervention activities was based on the Universal Design for Learning and on Teaching Guiding Activities. The actions provided the reflection/problematization on the contributions of the special education in the inclusive perspective, emphasizing the 
importance of acknowledging and knowing the potentialities of the many students in school. It was emphasized the importance of the connection of Mathematics with other areas of expertise for planning and coping with the reality in the inclusive context.

Keywords: Interdisciplinary PIBID. Inclusive education. Mathematics. Teacher training.

\section{INTRODUÇÃO}

O Programa Institucional de Bolsa de Iniciação à Docência (Pibid), tem como base legal a Lei no 9.394/1996, a Lei no 12.796/2013 e o Decreto oo 7.219/2010, e como objetivo "fomentar a iniciação à docência, contribuindo para o aperfeiçoamento da formação de docentes em nível superior, superior e para a melhoria da qualidade da educação básica pública brasileira" (PORTARIA nº 096/2013, Cap. 1, Arts. 1e e 2으).

A Portaria № 096/2013 atualizou as normas do Pibid, valorizando a participação em experiências inovadoras e de natureza interdisciplinar. Enfatiza o "desenvolvimento de ações que valorizem o trabalho coletivo, interdisciplinar e com intencionalidade pedagógica clara para o processo de ensino-aprendizagem" (Cap. II, Art. 6o, inciso II). Desse modo, permite que as instituições de ensino superior apresentem subprojetos interdisciplinares na intenção de "articular docentes de diferentes áreas, visando ao desenvolvimento de atividades integradas na escola conveniada e à promoção da formação interdisciplinar" (Art. 39, inciso VIII).

A proposta do Pibid/2013 da Universidade Estadual de Santa Cruz (Uesc), subsidiada em experiências anteriores (2009-2011), visou contribuir tanto com a formação inicial dos licenciandos, como na manutenção de um diálogo entre a educação básica e a universidade, para proporcionar melhoria na formação continuada dos professores em serviço.

No subprojeto Interdisciplinar, a temática da educação inclusiva foi escolhida, tendo em vista a necessidade da formação inicial e continuada de professores para atuar na diversidade, voltada para a compreensão das diferenças e potencialidades de cada estudante, de modo que o ensino favoreça a aprendizagem de todos. Nesse sentido, as Diretrizes Nacionais para a Educação Especial na Educação Básica (2001), bem como as Diretrizes Curriculares Nacionais para a Educação Básica 
(2010), ressaltam a importância da formação de professores para o desenvolvimento de práticas educacionais inclusivas.

Entretanto, apesar das bases legais referidas, Martins (2009 apud MARTINS, 2012, p. 30), enfatiza que "muitas instituições de ensino superior não se estruturaram no sentido de oferecer disciplinas e/ou conteúdos relativos ao tema nos seus cursos de licenciatura, enquanto que outras o fazem de maneira precária [...]".

Diante dessa realidade, o subprojeto Pibid Interdisciplinar - Educação Inclusiva destina-se a preencher uma lacuna ainda vigente nos currículos dos cursos de licenciatura da Uesc, no que tange à educação inclusiva, de forma a possibilitar aos licenciandos o embasamento teórico-prático e a reflexão sobre saberes/práticas inclusivas com base no (re)conhecimento das potencialidades dos estudantes público-alvo da educação especial.

Neste artigo, objetiva-se apresentar a organização do trabalho pedagógico do subprojeto Pibid Interdisciplinar - Educação Inclusiva, na área de Matemática, cujos planejamento e desenvolvimento das ações ocorreram de forma conjunta com as áreas de Letras e Pedagogia, no período de 2016 a 2018. Para tanto, são discutidas as possibilidades de formação de professores para a educação inclusiva. Em seguida, apresentada a orientação metodológica adotada, as experiências vivenciadas no campo da Matemática por essa equipe de coordenadores, e, por fim, as considerações finais.

\section{FORMAÇÃO PARA A EDUCAÇÃO INCLUSIVA: DILEMAS E POSSIBILIDADES}

A partir da década de 1990, o paradigma da educação inclusiva vem sendo estabelecido em muitos países (ONU, 2006; UNESCO, 1990), inclusive no Brasil (BRASIL, 1988; 1996; 2008; 2011; 2014; 2015). Para a Organização das Nações Unidas para Educação, Ciência e Cultura (Unesco), a educação inclusiva não é só um princípio, mas uma orientação geral que visa a "fortalecer a educação, com vista a um desenvolvimento sustentável, aprendizagem ao longo da vida para todos e acesso igual de todos os níveis da sociedade às oportunidades de aprendizagem" (UNESCO, 2008, p. 18). 
No Brasil, essa orientação tem sido encontrada nas legislações vigentes (BRASIL, 1996). A Lei de Diretrizes e Bases da Educação Nacional (LDBN, 1996, Art. 58) enfatizava que a educação especial devia ser oferecida preferencialmente na rede regular de ensino para os educandos "portadores de necessidades especiais".

Uma nova redação é dada pela Lei no 12.796/2013, distinguindo o públicoalvo da educação especial e estabelecendo o direito ao Atendimento Educacional Especializado (AEE) aos educandos com deficiência, com "transtornos globais do desenvolvimento e altas habilidades ou superdotação, a todos os níveis, etapas e modalidades, preferencialmente na rede regular de ensino" (Art. 4, inciso III). O AEE é definido como um serviço da Educação Especial na perspectiva inclusiva, que "identifica, elabora e organiza recursos pedagógicos e de acessibilidade que eliminem as barreiras para a plena participação dos estudantes público-alvo da educação especial, buscando complementar e/ou suplementar a sua formação" (BRASIL, 2008, p. 16).

Por sua vez, o Plano Nacional de Educação (Lei no 13.005/2014), na sua meta 4, reafirma a proposta de universalizar a educação, preferencialmente na rede regular de ensino, para todos os estudantes público-alvo da educação especial (de 4 a 17 anos).

A Lei Brasileira de Inclusão (LBI) - Estatuto da Pessoa com Deficiência (BRASIL, 2015) inaugura um novo paradigma em nosso país, quando se distancia de um "modelo médico", em que a deficiência é definida como doença que deve ser tratada/reabilitada, para apresentar um conceito baseado nos direitos humanos, que reconhece a deficiência, mas denuncia a estrutura social desigual. A pessoa com deficiência é aquela que tem impedimento de longo prazo "de natureza física, mental, intelectual ou sensorial, o qual, em interação com uma ou mais barreiras, pode obstruir sua participação plena e efetiva na sociedade em igualdade de condições com as demais pessoas" (BRASIL, 2015, p. 1).

Assim, a deficiência é uma condição da pessoa, evidenciada quando ela entra em contato com barreiras nos campos social e educacional. O esforço para lidar com a deficiência deve ser bilateral: da pessoa e da sociedade. 
Apoiados nessa concepção, vários movimentos, em torno do funcionamento das instituições sociais e nas relações entre sujeitos, têm se estabelecido nos últimos anos, voltados a (re)pensar a formação dos profissionais da educação, a fim de compreender não apenas os aspectos de valorização desses sujeitos, como também os aspectos atinentes à sua instrumentalização quanto às demandas socioculturais.

Assim, o papel da educação, no ensino superior, enquanto formação pedagógica, deve se posicionar a partir de uma perspectiva da diferença, calcada em um novo paradigma social, outras posturas de educandos e educadores.

Mas como promover uma educação mais inclusiva, no contexto escolar, considerando uma pedagogia da diferença? As políticas públicas nacionais preconizam "o acesso, a participação e a aprendizagem de todos os estudantes" (BRASIL, 1996; 2008; 2011; 2015). O acesso é garantido, mas a participação e a aprendizagem dependem de outros fatores, como, por exemplo, a própria postura e formação do docente.

A LDBN (1996, Cap. V, Art. 59, inciso III) traz que as instituições de ensino devem assegurar: "Professores com especialização adequada em nível médio ou superior, para atendimento especializado, bem como professores do ensino regular capacitados para a integração desses educandos nas classes comuns".

A LBI (BRASIL, 2015, Art. 28, inciso X)) recomenda a "adoção de práticas pedagógicas inclusivas pelos programas de formação inicial e continuada de professores e oferta de formação continuada para o atendimento educacional especializado".

Observa-se que as duas leis mencionam a formação inicial dos cursos de graduação, mas ainda priorizam a especialização de professores para subsidiar o AEE.

De acordo com Denari e Sigolo (2016, p. 19), todos os envolvidos no processo de educação são importantes, mas os docentes assumem um protagonismo, nesse processo, visto que permanecem sempre "no olho do furacão" e não podem ser considerados apenas como simples executores de propostas educacionais, pois a complexidade inerente à sua profissão evidencia-se na prática 
diária da sala de aula, quando selecionam conteúdos, planejam, definem objetivos, estratégias e recursos para gerir sua classe e lidar com os desafios que surgem relacionados com o ensino e a aprendizagem.

Para caracterizar os professores que atuam ou devem atuar no contexto inclusivo, as Diretrizes Nacionais para a Educação Especial na Educação Básica (2001), apresentam a distinção entre as competências necessárias dos professores da classe comum e professores da educação especial. De acordo com o Art. 18, $\S$ 10:

São considerados professores capacitados para atuar em classes comuns com alunos que apresentam necessidades educacionais especiais aqueles que comprovem que, em sua formação, de nível médio ou superior, foram incluídos conteúdos sobre educação especial adequados ao desenvolvimento de competências e valores para: I - perceber as necessidades educacionais especiais dos alunos e valorizar a educação inclusiva; II - flexibilizar a ação pedagógica, nas diferentes áreas de conhecimento, de modo adequado às necessidades especiais de aprendizagem; III - avaliar continuamente a $f$ do processo educativo para o atendimento de necessidades educacionais especiais; IV - atuar em equipe, inclusive com professores especializados em educação especial. (BRASIL, 2001, grifos do original).

E no mesmo artigo, § 2으, são considerados professores especializados em educação especial:

Aqueles que desenvolveram competências para identificar as necessidades educacionais especiais para definir, implementar, liderar e apoiar a implementação de estratégias de flexibilização, adaptação curricular, procedimentos didáticos pedagógicos e práticas alternativas, adequados ao atendimento das mesmas, bem como trabalhar em equipe, assistindo o professor de classe comum nas práticas que são necessárias para promover a inclusão dos alunos com necessidades educacionais especiais. (BRASIL, 2001).

Os professores especializados (ou da educação especial) devem comprovar formação em cursos de Licenciatura em Educação Especial; em Licenciatura nos Anos Iniciais do Ensino Fundamental, ou em complementação de estudos ou pósgraduação em áreas específicas da educação especial.

Atualmente, os professores da educação especial exercem sua função quase que exclusivamente no AEE. Em alguns municípios do Brasil, esses professores 
podem atuar como assistentes dos professores na classe comum, no modelo de ensino colaborativo, ou prestar serviços de itinerância em outras escolas.

A oferta do AEE realiza-se na rede pública municipal, ou estadual, em salas de recursos multifuncionais, definidas como ambientes dotados de equipamentos, mobiliários, materiais didáticos e pedagógicos. Ocorre no turno oposto da aula do estudante, devendo integrar a proposta pedagógica da escola, e envolver a participação da família, para garantir pleno acesso e participação dos estudantes. Entretanto, pode ser realizado em centro de atendimento da rede pública, em instituições comunitárias ou filantrópicas (BRASIL, 2008; 2011).

No contexto atual da escola, a responsabilidade pela inclusão muitas vezes compete aos professores da educação especial que atuam no AEE. Muniz (2018, p. 68) analisou as relações pedagógicas estabelecidas entre professor, intérprete de Língua Brasileira de Sinais (Libras) e estudante surdo na aula de Matemática e destaca que os professores entrevistados concebem a inclusão como localizada no AEE: "Seu papel enquanto professor parece não existir, ele situa o surdo no lugar dele, segregando-o na própria escola, quando afirma: eles têm uma sala individual para eles fazerem tudo".

Desse modo, observamos que as atribuições dos professores da educação especial tornam-se abrangentes, em comparação com os professores da sala comum, pois, além de serem considerados a própria "inclusão", necessitam de um repertório de competências para atender diretamente às especificidades educacionais dos estudantes público-alvo da educação especial.

Considerados esses aspectos, cabem questionamentos: Qual deve ser a sua formação? Como pode atuar de forma mais articulada com o professor da sala comum e com o sistema escolar para compartilhar seus saberes e atribuições?

Segundo Denari e Sigolo (2016), não há um consenso em relação ao tipo de formação desse profissional; sobre a adoção de uma abordagem generalista ou especialista. Mas há consenso em relação à necessidade da formação de professores para prover a educação inclusiva.

Para responder a essa demanda, as autoras apontam caminhos possíveis, na formação inicial e na continuada, dentre eles: 
Conhecimento pedagógico geral, englobando saberem teóricos e práticos para promover uma atuação "mais humanizada, coerente e consistente no respeito à diversidade e às características dos estudantes; a concepção da educação como um fenômeno social"; conhecimento sobre adaptações no processo de ensino considerando as individualidades, os conteúdos e recursos materiais; conhecimentos sobre os pressupostos teóricos e práticos sobre as práticas inclusivas e sobre os projetos político-pedagógicos; a troca de experiências através da interlocução entre estudantes, professores especialistas e professores do ensino regular; a compreensão dos processos de ensino e aprendizagem como um termômetro para o desenvolvimento de habilidades e competências. (DENARI; SIGOLO, 2016, p. 28).

Ao promover tais discussões, revela-se a necessidade de dissociar a formação em educação inclusiva apenas para o campo especializado de atendimento, mas reconhecer que a realidade social em que estamos inseridos incorpora o atendimento às pessoas com deficiência em todos os espaços sociais e culturais, além do especializado ofertado nas escolas.

Apesar dos investimentos na implantação de Salas de Recursos Multifuncionais, destinadas ao AEE; e na formação continuada de professores especializados para prover esse atendimento, os demais professores da escola, responsáveis pelas salas comuns, ainda se sentem despreparados para lidar com os estudantes com deficiência, além de outras especificidades e complexidades que a sala de aula Ihes apresenta (NASCIMENTO; CORREIA; PORTELA, 2014).

Para os professores da sala de aula comum, desde pedagogos a licenciados das diversas áreas de conhecimento, as exigências e os desafios enfrentados para atender ao público-alvo da educação especial não são menores, uma vez que a sua formação inicial não tem contemplado de forma mais ampla o debate da educação inclusiva.

Entretanto, o desenvolvimento de projetos dentro de uma perspectiva de educação inclusiva envolve um "conjunto de desafios" para o professor da escola comum, porque algumas das competências "eram do domínio exclusivo dos professores da educação especial ou das escolas especiais" e, agora, as responsabilidades devem ser compartilhadas por toda a equipe escolar, assim, surgem novas indagações sobre quais são as competências que o professor da 
escola comum "deve adquirir e dominar" para enfrentar essa realidade (RODRIGUES; LIMA-RODRIGUES, 2011, p. 45).

Essa discussão envolve a formação inicial e continuada de professores da escola básica. Glat e Pletsch (2010, p. 349) advertem que o desafio para as universidades é "formar profissionais educadores que não sejam apenas instrumentos de transmissão de conhecimentos, mas, sobretudo, de novas atitudes e práticas que valorizem a diversidade humana".

A lógica homogeneizadora da ação docente baseada "na transmissão de conhecimentos teóricos e fragmentados entre si, os quais tendem a não apresentar relevância social tanto para a escola quanto para o estudante" (DUK, 2006, p. 22), não contribui para uma formação inicial e continuada capaz de instrumentalizar os futuros docentes para os desafios da escola hoje.

No campo das formações inicial e continuada do professor, novas racionalidades são exigidas e ainda estão em curso. Busca-se romper com o modelo da racionalidade técnica, baseado no modelo " $3+1$ " (três anos de formação específica e um ano de formação pedagógica) (MOREIRA; DAVID, 2005), para aproximar-se do modelo da racionalidade prática ou crítica, em que se valorizam os estudos sobre os saberes docentes mobilizados na prática, sobre o professor reflexivo/pesquisador, e o trabalho colaborativo de pesquisa com (ou dos) os professores da escola básica (ESPINOSA; FIORENTINI, 2005).

Para Santos (2017, p. 35), uma formação continuada no campo da Matemática deve situar os professores nas novas tendências pedagógicas nessa área, por exemplo, o trabalho com investigações matemáticas. As propostas de formação precisam "superar a dicotomia entre teoria e prática", e reconhecer os professores como protagonistas de seu desenvolvimento profissional e não atores passivos "diante de formações prescritivas e esvaziadas de sentido".

A formação inicial dos docentes precisa, portanto, contemplar a perspectiva do professor reflexivo e crítico, bem como inserir os componentes da educação inclusiva em toda a estrutura formativa, seja a partir de um currículo atento para disciplinas que atendam a essa vertente, seja na organicidade de projetos, 
pesquisas, programas, extensões, para que, ao longo de sua formação, os futuros docentes estejam ambientados e estimulados a desenvolver ações inclusivas.

Portanto, as licenciaturas, incluindo a de Matemática, devem revisar seus projetos acadêmicos curriculares e suas práticas, e considerar o que indicam as Diretrizes Curriculares para Educação Básica (BRASIL, 2010), sobre a base conceitual da organização curricular na modalidade de educação especial, em seu Art. 29, inciso II:

Os sistemas e as escolas devem criar condições para que o professor da classe comum possa explorar as potencialidades de todos os estudantes, adotando uma pedagogia dialógica, interativa, interdisciplinar e inclusiva e, na interface, o professor do AEE deve identificar habilidades e necessidades dos estudantes, organizar e orientar sobre os serviços e recursos pedagógicos e de acessibilidade para a participação e aprendizagem dos estudantes.

E, principalmente, devem se fundamentar nas novas Diretrizes Curriculares Nacionais para a formação inicial em nível superior e para a formação continuada (Resolução CNE/CP ne 2/2015). Segundo Dourado (2015, p. 301), as diretrizes resumem concepções defendidas há anos pelas entidades da área da educação, trazendo um avanço considerável para a formação de professores e reafirmam:

\begin{abstract}
Uma base comum nacional para a formação inicial e continuada cujos princípios devem ser considerados na formulação dos projetos institucionais de formação inicial e continuada - incluindo a licenciatura - por meio da garantia de concepção de formação pautada tanto pelo desenvolvimento de sólida formação teórica e interdisciplinar em educação de crianças, adolescentes, jovens e adultos(as) e nas áreas específicas de conhecimento científico quanto pela unidade entre teoria e prática e pela centralidade do trabalho como princípio educativo na formação profissional, como também pelo entendimento de que a pesquisa se constitui em princípio cognitivo e formativo e, portanto, eixo nucleador dessa formação.
\end{abstract}

Dessa forma, a formação para a educação inclusiva deve estar pautada nessas diretrizes, de forma a ultrapassar a lógica homogeneizadora da ação docente para contemplar uma formação baseada na interdisciplinaridade, na pesquisa, na unidade entre a teoria e a prática e, principalmente, na articulação permanente com a educação básica. 


\section{SUBPROJETO INTERDISCIPLINAR: CARACTERIZAÇÃO E ASPECTOS METODOLÓGICOS}

O subprojeto interdisciplinar Educação Inclusiva teve início em outubro de 2016 e término em março de 2018. O objetivo foi desenvolver a iniciação à docência, atuando no AEE da escola conveniada, sem perder de vista a sala de aula regular e o sistema escolar.

A escola conveniada atendia a 705 estudantes das séries finais do Ensino Fundamental (6o ao 9ㅇ ano) e da Educação de Jovens e Adultos (EJA). O AEE abrangia estudantes com deficiência intelectual (15), deficiência auditiva (11), deficiência visual (1), autismo (2), síndrome de Down (1), cadeirante (1), paralisia cerebral (1); com 18 matriculados na escola e 14 de escolas próximas.

Participaram dez bolsistas de Iniciação à Docência (ID). Cinco eram da Licenciatura em Letras e cinco de Matemática; duas professoras Supervisoras (SU) do AEE, licenciadas em Letras, com especialização em educação especial; dois Coordenadores de Área (CA), um de Letras e outro de Matemática. Após breve período, dois bolsistas de Matemática foram substituídos por dois de Pedagogia, e inserida na equipe uma coordenadora de área de Pedagogia.

A orientação metodológica adotada foi a investigação-ação, conceito que é multifacetado, pois vários autores o abordam de diferentes formas, entretanto, é um caminho metodológico que reforça "o desenvolvimento de competências investigativas docentes, através da análise reflexiva da prática" (MACHADO, 2014, p.16), em que o professor-investigador pode realizar intervenções de ensino e aprendizagem para desenvolver as competências dos estudantes. Atualmente, 0 conceito está associado "a um potencial autorreflexivo, participado e crítico, numa perspectiva de transformação social dos agentes envolvidos" (MACHADO, 2014, p. 32).

Dessa forma, a equipe de coordenadores planejou e executou a proposta de investigação-ação do subprojeto Interdisciplinar, com a formação de grupos de estudo; observação/monitoria; planejamento; intervenções e sistematização. Em cada item a seguir, são detalhadas essas ações: 
1. Grupo de Estudos: Os participantes discutiram os marcos legais da educação inclusiva; a história e o público-alvo da educação especial; a definição e as especificidades pedagógicas para cada área (Letras, Matemática, Pedagogia); o fichamento de artigos científicos sobre as metodologias de ensino; as especificidades pedagógicas dos estudantes com deficiência; a abordagem do Desenho Universal para a Aprendizagem (DUA) (ROSE; MEYER, 2002); e o planejamento baseado em atividades orientadoras de ensino (MOURA, 1996; MOURA et al., 2016).

2. Observação/Monitoria: Os bolsistas ID participaram em duplas ou trio, de forma a trabalhar como uma equipe interdisciplinar, observando e prestando monitoria no AEE, enquanto as supervisoras atendiam aos estudantes. Também observaram aulas na sala regular para subsidiar as intervenções nesta sala. Houve também visitações a um Centro de Apoio Pedagógico (CAP) de referência no AEE, na região do entorno da Universidade.

3. Planejamento: Os coordenadores, bolsistas ID e as supervisoras planejaram uma apresentação do subprojeto para a escola e seus estudantes; também elaboraram um roteiro de observação não participante para ser utilizado na sala de aula regular e no AEE; discutiram o planejamento diário da monitoria no AEE; bem como todas as intervenções que seriam realizadas tanto na escola como em eventos.

4. Intervenções: Os bolsistas ID desenvolveram Atividades Orientadoras de Ensino no AEE e na sala de aula regular desses estudantes. Participaram também do Workshop Educação Inclusiva: Atividade de Ensino Usando Vídeos com ênfase na Matemática, evento realizado em uma das escolas conveniadas, no dia 30 de setembro de 2017, com a presença de professores, gestores e estudantes da escola.

Nesse evento, os bolsistas ministraram e participaram da oficina 1: Atividade Orientadora de Ensino (AOE): História da Contagem e Sistemas de Numeração (Figura 1); da oficina 2: Atividade Orientadora de Ensino (AOE): Economia Doméstica e Matemática Financeira através do Software Scracht; e da oficina 3: 
Introdução à Libras. Além disso, exibiram o painel: Bases Legais da Educação Especial na Perspectiva Inclusiva: Apresentação de Experiências.

Os coordenadores de área e as supervisoras ministraram uma mesa-redonda intitulada: O Debate da Educação Especial na Perspectiva Inclusiva. Em outra escola conveniada, a equipe de bolsistas apresentou o Seminário Educação Inclusiva, na jornada pedagógica ocorrida em fevereiro de 2018.

\section{Figura 1 - Oficina 1: Atividade Orientadora de Ensino:} História da Contagem e Sistemas de Numeração

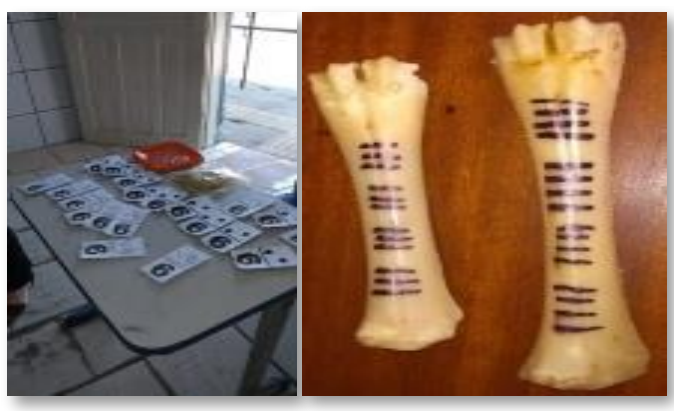

Fonte: Arquivo dos autores.

5. Sistematização: Consistiu na organização da vivência em forma de comunicação oral, em eventos, oficinas pedagógicas; boletins informativos com as bases legais e especificidades sobre o público-alvo da educação especial para serem divulgados na escola; elaboração e apresentação de relatório sobre a observação desses estudantes na sala regular e no AEE; organização de eventos nas escolas, como os citados anteriormente

Além disso, a equipe participou do III Seminário Internacional Cooperação Brasil/Quebec - Diversidade e Educação Inclusiva: Perspectivas Interdisciplinares e Interepistêmicas, em setembro de 2017, na Universidade Federal do Sul da Bahia (UFSB); e do II Seminário Institucional Pibid e VII Seminário Baiano do Pibid, em janeiro de 2018, na Uesc. Nesses eventos, apresentaram banners, comunicações orais e os minicursos: Educação Inclusiva: foco na Deficiência Visual; Descobrindo o Universo Down; e Educação Inclusiva: Surdez.

$\mathrm{Na}$ Universidade, o grupo composto pelos bolsistas (Iniciação a bolsista - ID, SU e CA) reunia-se semanalmente, durante duas horas, para desenvolver as ações 
1, 3 e 5. Os CAs visitavam as escolas para orientação das SUs e supervisão dos estudantes, para avaliar as ações 2 e 4.

\section{AS EXPERIÊNCIAS ENVOLVENDO O ENSINO DE MATEMÁTICA}

Nesta seção, são apresentados dois exemplos de experiências vivenciadas pela equipe do Pibid Interdisciplinar - Educação Inclusiva, no contexto da Matemática. A primeira apresenta uma intervenção na aula de Matemática baseada no DUA. A segunda aborda os estudos teóricos e o planejamento de uma AOE.

\subsection{UMA INTERVENÇÃO DE ENSINO NA AULA DE MATEMÁTICA BASEADA NO DESENHO UNIVERSAL PARA A APRENDIZAGEM}

O conceito de Desenho Universal para a Aprendizagem (DUA), geralmente atribuído a David Rose, Anne Mayer e seus colegas do Center for Applied Special Technology (CAST, 2011), refere-se a princípios e estratégias destinadas ao desenvolvimento curricular.

Nessa abordagem, os princípios do DUA aplicados a ambientes, produtos e serviços desenvolvidos no contexto da arquitetura, são adotados na educação, visando a garantir o acesso à aprendizagem de todos. O DUA está ancorado em contribuições de diversas áreas do conhecimento: neurociências, psicologia do desenvolvimento e as ciências cognitivas, e relaciona-se com:

Práticas de ensino a desenvolver junto de alunos com e sem deficiência, centrando-se na dimensão pedagógica. Trata-se, portanto, de uma abordagem curricular que procura reduzir os fatores de natureza pedagógica que poderão dificultar o processo de ensino e de aprendizagem, assegurando assim o acesso, a participação e o sucesso de todos os alunos. (NUNES; MADUREIRA, 2015, p. 132).

As intervenções pedagógicas devem envolver todos os alunos, dando-lhes acesso ao currículo, com o objetivo final de promover o progresso de todos, oportunizando ao professor um "modelo de intervenção que ajuda a compreender como se pode criar um currículo que vá ao encontro das necessidades de todos os 
alunos" (NUNES; MADUREIRA, 2015, p. 7). Segundo as autoras, o DUA baseia-se em três princípios:

1) Proporcionar múltiplos meios de envolvimento: estimular o interesse dos alunos e motivá-los para a aprendizagem recorrendo a múltiplas formas; 2) Proporcionar múltiplos meios de representação: apresentar a informação e o conteúdo em múltiplos formatos para que todos tenham acesso; 3) Proporcionar múltiplos meios de ação e expressão: permitir forma alternativas de expressão e demonstração das aprendizagens, por parte dos alunos. (NUNES; MADUREIRA, 2015, p. 135).

O primeiro princípio relaciona-se com "o envolvimento e a motivação", visto que, sem estar motivado, o estudante não inicia o processo de aprender. 0 professor deve buscar formas variadas de envolver o estudante em tarefas, individuais ou em grupo, de acordo com as preferências de cada um. Portanto, nessa tarefa, precisa perceber os interesses da turma e ajudar os alunos a persistir neles, elaborando tarefas e projetos para que o estudante possa "fazer", "criar", reinventar o conhecimento. Por exemplo, a utilização de jogos pode ser um recurso que pode envolver todos os estudantes, dependendo das adaptações feitas.

O segundo princípio refere-se à forma de apresentar os conteúdos. A representação do conhecimento por meio de uma abordagem multimodal, pode facilitar a percepção de cada estudante, pois cada um percebe o mundo de forma diferente. Por exemplo, alunos com surdez; deficiência visual; motora; intelectual; necessitam de aparatos de comunicação/linguagem diferentes, seja oral, tátil ou visual. A imagem; filmes com legenda, figuras e textos; uso de softwares; material concreto; podem ser explorados com vistas a apresentar os conceitos objetivados. A Matemática, por si só, é rica em representações algébricas, pictóricas, diagramas, gráficas, etc.

O terceiro princípio refere-se à avaliação, que não deve ser restrita "à medida" do desempenho, mas ao processo como um todo. Na execução das tarefas, deve ser considerada para identificar os conceitos que estão elaborando ou ainda em via de elaboração. O professor deve estar atento às dimensões da avaliação, que devem ser diversificadas: oral, em grupo, individual, tendo em vista que os estudantes se diferenciam no modo de expressar suas aprendizagens, pois uns têm 
facilidade com a exposição oral, enquanto outros não conseguem escrever bem (deficiência motora).

Entendemos a importância de trazer para o contexto da escola inclusiva a abordagem do DUA, que propõe aos professores formas diferenciadas de considerar a diversidade de estudantes, em termos de currículo e planejamento de aula.

Assim, no contexto deste Pibid, uma equipe interdisciplinar de bolsistas ID, sob a supervisão das bolsistas supervisoras, desenvolveu uma ação de investigação, considerando a abordagem do DUA: diversidade nos meios de envolvimento, representação e ação/expressão. O objetivo desta atividade foi produzir uma intervenção de ensino focando a inclusão de estudantes com Síndrome de Down e Déficit Intelectual na aula de Matemática do 8o ano do Ensino Fundamental.

A investigação foi desenvolvida segundo as etapas: 1) Observação não participante de duas aulas de Matemática abordando os aspectos: interação professor-estudante, estudante-estudante, competências/dificuldades no conteúdo, metodologias do professor; 2) Elaboração de um plano de intervenção para a turma regular para atender à demanda identificada na observação, ou seja, as dificuldades na compreensão das quatro operações básicas; 3) A intervenção foi a aplicação do jogo Nunca dez, utilizando como recurso o material dourado. Esse jogo é usado para facilitar a compreensão da passagem da unidade para a dezena; da dezena para a centena; da centena para o milhar; e explorar as habilidades dos estudantes no sistema posicional.

$\mathrm{Na}$ etapa de observação, na primeira aula, foi possível perceber que os estudantes não estavam sendo incluídos, pois não participavam, por falta de solicitação da professora regente, conforme o relatório de observação de uma bolsista:

Exercícios retirados do livro didático foram transcritos no quadro e resolvidos pelo professor juntamente com a classe. No entanto, os alunos com Deficiência Intelectual, não foram incluídos no diálogo em nenhum momento. Apesar de parecer apenas um objeto decorativo da sala de aula [...] souberam se comportar melhor que a classe inteira junta [...] mas não participavam ativamente dos debates, já que em nenhuma hora foram questionados ou 
estimulados pelo professor regente a participar. (Relato da observação, bolsista Pibid-Letras, 2017).

Essa experiência causou impacto na estudante, provocando-a à reflexão sobre a necessidade de buscar recursos didáticos e metodológicos para efetivar a inclusão na sala: "Saí dessa aula com o coração apertado, mas a mente fervendo de ideias que, se bem pensadas, aceitas e executadas, podem ajudar tanto o aluno como o professor que não é de todo o vilão". A observação da segunda aula revelou uma postura diferente da professora, provocando mais participação do estudante com Deficiência Intelectual (DI):

\begin{abstract}
A próxima aula foi totalmente o oposto da relatada acima, foi realizado um teste de matemática e a turma nem parecia a mesma, pois o silêncio e o respeito mútuo eram de encantar. O aluno com DI foi tratado como qualquer outro membro da classe, seu teste era diferenciado respeitando o seu grau de conhecimento. A professora esteve ao seu lado explicando-lhe o que ele deveria fazer, seu teste foi sobre subtração e todas as respostas foram pensadas por ele, com a educadora apenas Ihe apontando o caminho [...]. (Relato da observação, bolsista Pibid-Letras, 2017).
\end{abstract}

Segundo o relato dessa bolsista, "a professora se mostrou muito aberta e feliz com a presença dos 'pibidianos' na escola, pois trazem novidades, o que a fez se apresentar disposta a trabalhar em parceria conosco". Dessa forma, foi planejada uma intervenção pelos bolsistas, em parceria com a regente, abordando as dificuldades desses estudantes. Foi priorizado o trabalho em grupo, para promover a interação entre os estudantes.

Para a intervenção de ensino, a turma foi dividida em quatro grupos que deveriam resolver as questões ditadas pelos bolsistas (envolvimento e motivação) com o auxílio do material dourado (forma de representar o conteúdo). Antes de proceder ao jogo, os bolsistas apresentaram cada peça, questionando: "Quantos cubinhos tem em cada barra, em cada placa e no cubo maior? Quantas barras tem em uma placa? Quantas barras tem o cubo maior? Como achou o resultado? (forma de envolver e motivar). Cada grupo discutiu essas questões e respondeu no papel (forma de expressão e comunicação). 
As regras do jogo foram apresentadas aos educandos e cada grupo recebeu dois dados e peças do material dourado; em cada grupo, quem tirava o número maior de pontos, começava o jogo e pegava a quantidade de cubinhos (unidades) corresponde aos números de pontos dos dados. Nas rodadas seguintes, os pontos se acumulavam ao resultado anterior. A regra é: "nunca dez!". Quando um jogador obtinha 10 cubinhos, os trocava por uma barra; quando obtinha 10 barras, as trocava por uma placa (centena); e quando obtinha 10 placas, as trocava pelo cubo maior (cubo de milhar). Vencia o jogo quem primeiro conseguia o cubo maior (cubo de milhar).

Após algumas rodadas, os bolsistas ditaram alguns números e solicitaram que os estudantes representassem com o material dourado e vice-versa, fazendo a leitura do número representado no material dourado (forma de representar). Também ditaram algumas operações (adição e subtração) sem reserva e com reserva, com recurso e sem recurso. Em seguida, cada grupo explicou sua resolução oralmente, utilizando esse material (formas de expressão e comunicação) (Fig. 2).

Figura 2 - Intervenção na aula de matemática: orientação da ação e exposição dos estudantes

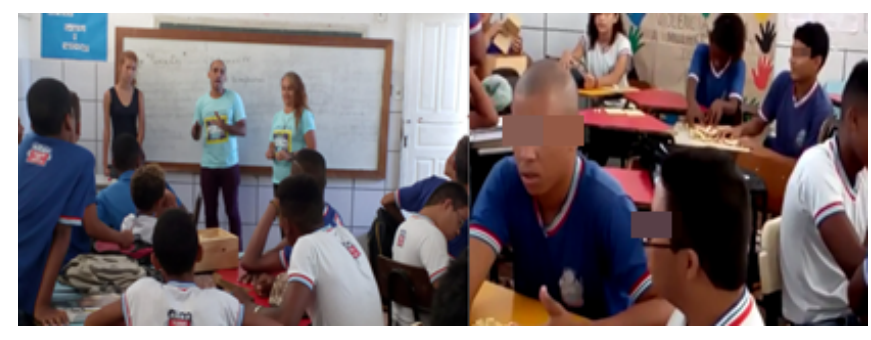

Fonte: Arquivo dos autores.

Nessa atividade, constatou-se que os estudantes com DI e com síndrome de Down estavam motivados para participar, colaborando uns com os outros, inclusive, fizeram espontaneamente a exposição do seu grupo, mostrando que é possível encontrar diferentes maneiras de chegar a um mesmo resultado por meio das operações básicas. Assim, a proposta do jogo, coordenada com a discussão/ resolução de desafios em grupo, favoreceu a inclusão desses estudantes. 
A experiência de iniciação docente interdisciplinar, unindo perspectivas das áreas de Matemática e Letras, enriqueceu tanto o processo de elaboração da intervenção como o de sua aplicação. Enfim, verificamos que a inclusão pode ser implementada com ações simples, por professores de áreas distintas, levando em conta as especificidades dos estudantes por meio dos princípios do DUA.

\subsection{PLANEJANDO ATIVIDADES ORIENTADORAS DE ENSINO}

A observação na sala de aula dos estudantes surdos mostrou que a presença do intérprete é primordial no contexto educacional inclusivo, pois muitos professores não conhecem Libras nem sabem lidar com as especificidades da surdez: "A relação professor-alunos surdos é muito pouca, justamente pelos professores não terem conhecimento e uso da Libras. O professor precisa repassar as perguntas para o intérprete, que, por sua vez, faz com que os alunos interajam na aula" (Relato da observação, bolsista Pibid-Letras, 2017). Embora o intérprete educacional tenha que lidar com as questões de ensino, seu papel tem se confundido com o de professor:

A intérprete fica responsável por auxiliar diretamente os alunos, tanto na explicação, quanto na leitura dos conteúdos. Acaba por cumprir o papel do docente, pois precisa assimilar e interpretar o conteúdo pra poder repassar para os alunos surdos. No assunto Plano Cartesiano e pares ordenados, mais uma vez, a intérprete precisou assimilar o conteúdo e assim repassar e auxiliá-los na produção da atividade. (Relato de observação, bolsista Pibid-Letras, 2017).

O aluno a todo o momento se comunicava com o intérprete, ele tinha a necessidade de que todas as questões e alternativas fossem passadas para ele pela língua de sinais. Qualquer dúvida tida por ele era explicada pelo intérprete. (Relato de observação, bolsista PibidMatemática, 2017).

As considerações pontuadas pelos bolsistas mostram a importância do professor interagir com o estudante surdo e com o intérprete; na medida do possível dominar Libras; e não deixar o intérprete assumir o protagonismo do ensino que não é da sua competência. O trabalho pedagógico com estudantes surdos nas escolas comuns deve favorecer um ambiente bilíngue, em que a Libras seja a primeira língua e a Língua Portuguesa a segunda, na modalidade escrita; o papel do AEE é fundamental para complementar as necessidades dos estudantes e subsidiar o trabalho dos professores na sala de aula comum (BRASIL, 2011). 
Segundo Damázio (2007, p. 26), o planejamento no AEE deve ser "elaborado e desenvolvido conjuntamente pelos professores que ministram aulas em Libras, professor de classe comum e professor de Língua Portuguesa para pessoas com surdez".

Nesse contexto, os relatos das observações dos bolsistas ID foram objeto de reflexão nas reuniões com os CA e SU, na busca por um planejamento conjunto. $\mathrm{O}$ objetivo era apresentar alternativas de atividades tanto para o professor de Matemática como para o professor do AEE, contemplando estudantes com DI e surdos. Dessa forma, foram desenvolvidos estudos teóricos sobre planejamento de ensino por meio de AOE (MOURA, 1996).

A síntese desse estudo e um exemplo de AOE elaborada pelos bolsistas, foram apresentados aos professores de Matemática e do AEE para que pudessem aplicá-los tanto no atendimento como na sala de aula comum.

A AOE é "o conjunto articulado da intencionalidade do educador que lançará mão de instrumentos e estratégias que lhe permitirão uma maior aproximação entre sujeitos e objeto de conhecimento" (MOURA, 1996, p. 19).

Nessa perspectiva, o professor organiza as atividades de acordo com os conteúdos, as dificuldades e as respostas dos estudantes, visando a conduzi-los a um nível mais avançado. Isso requer definir "procedimentos de como colocar os conhecimentos em jogo no espaço educativo; e eleger instrumentos auxiliares de ensino: os recursos metodológicos adequados a cada objetivo e ação (livro, giz, computador, ábaco, etc.)" (MOURA, 2001, p. 155).

Segundo Moura (1996, p. 19), a AOE deve conter: I) A síntese histórica do conceito: em que o professor apresenta a história do conceito, mostrando a construção desse bem como as relações sociais envolvidas na criação e solução de problemas; II) Problema desencadeador: são situações de aprendizagem propostas aos estudantes. Os professores podem usar uma história, lenda, notícia, que contenha conceitos matemáticos, um jogo ou situações emergentes, isto é, questões ou observações do cotidiano ou da sala de aula que podem despertar a aprendizagem; III) Síntese coletiva: envolve a discussão das soluções pelos 
estudantes com a mediação do professor. Os processos de síntese, ao longo da atividade, são momentos de avaliação permanente para quem ensina e aprende.

Os bolsistas ID, sob a supervisão das professoras SU, desenvolveram a AOE de Matemática: Trabalhando a Correspondência Quantidade-Numeral. Para tanto, apresentaram uma síntese histórica do conceito e o problema desencadeador, conforme descrito a seguir.

\section{l) A Síntese histórica do conceito}

Nossas primeiras concepções de número surgiram há milhares de anos, na idade da pedra, ou período paleolítico. Durante muitos anos, os homens viviam em cavernas, em condições quase idênticas à dos animais e as suas principais energias eram guiadas para o processo elementar de recolher alimentos onde fosse possível encontrá-los. Em todas as culturas e sociedades, mesmo as mais rudimentares, nota-se algum conceito de número e, a ele associado, algum processo de contagem. Pode-se dizer que o processo de contagem consistia, a princípio, em fazer corresponder os objetos a serem contados com os objetos de algum conjunto: os dedos das mãos, dos pés, ou pedras.

Com o passar do tempo, surgiu a necessidade da contagem de uma quantidade maior de objetos, por exemplo, número de dias, árvores, cabeça de gados, etc. O homem percebeu que era preciso sistematizar o processo de contagem, e os povos de diversas partes do mundo desenvolveram vários tipos de sistemas de contagem. Estabeleceu-se, então, um conjunto de símbolos, com algumas regras que permitiam contar, representar e enunciar os números. Alguns desses conjuntos continham cinco, outros dez, doze, vinte ou até sessenta símbolos, chamados de "símbolos básicos".

Atualmente, o processo de contagem consiste em fazer corresponder os objetos a serem contados com o conjunto dos números naturais. Para se chegar à forma atual, aparentemente tão semelhante à anterior, foram necessárias duas grandes conquistas que estão intimamente relacionadas: o conceito abstrato de número e uma representação adequada deles (SOUZA, 2008).

II) Problema desencadeador 
O Jogo: Cada dupla recebe 11 fichas e 11 pregadores (Fig. 3) e discute sobre quantas cenouras têm na imagem e qual sinal numérico corresponde a esse número. Os estudantes contam e associam a quantidade de cenouras ao símbolo numérico. A dupla que termina primeiro, ganha o jogo.

Figura 3 - Material utilizado: pregadores em Libras e fichas

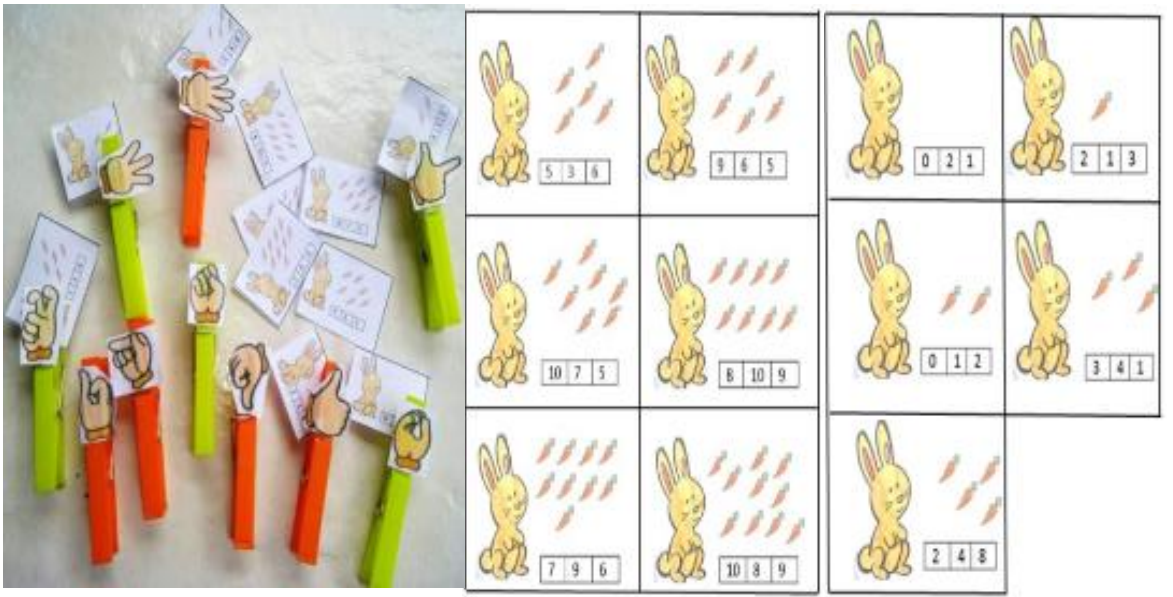

Fonte: Elaborado pelos autores.

Variação do jogo: No caso da participação de estudantes cegos, o sinal dos pregadores pode ser substituído por números em braile e as figuras nas cartelas podem estar em alto relevo.

Objetivo: Aprender os sinais dos números em Libras e os símbolos numéricos em correspondência com as quantidades.

Conteúdos: Contagem e percepção numérica.

III) Síntese coletiva

Ao preencher o tabuleiro, a dupla poderá discutir as dificuldades que tiveram em associar a quantidade com o sinal. Os professores especializados das salas de atendimento sabem que há muita dificuldade na realização dessas ações. É sugerido que o professor proponha uma discussão sobre os conhecimentos adquiridos nessa atividade, de forma a sempre problematizar e incentivar o conhecimento de Libras. 


\section{CONSIDERAÇÕES FINAIS}

Refletir sobre a realidade da escola e os aspectos de formação dos docentes que nela potencialmente vão atuar enquanto educadores permitiu-nos iniciar importante discussão sobre projetos institucionais que compartilhem a formação a partir de pontes estabelecidas entre o público-alvo, os professores, e os espaços formais de educação.

O trabalho interdisciplinar e colaborativo nas áreas possibilitou a ressignificação de sentidos para os bolsistas de iniciação à docência; os professores supervisores; os coordenadores de área; e os professores de Matemática da escola. O estudo sobre o DUA e o planejamento das AOE (abordagem oriunda do contexto do ensino de Matemática), envolveu os bolsistas de variadas áreas. Os bolsistas de Matemática participaram de discussões e atividades sobre letramento no $A E E$, propostas por bolsistas de Letras e Pedagogia, e vice-versa.

As ações proporcionaram a reflexão/problematização sobre os aportes da educação especial na perspectiva inclusiva, ressaltando a importância de (re)conhecer as potencialidades dos diversos estudantes na escola básica.

O Pibid Interdisciplinar - Educação Inclusiva veio ocupar uma lacuna nas licenciaturas referidas, considerando que essas ainda não contemplam, a fundo, essa temática. Assim, esse processo possibilitou:

- Vivenciar outra racionalidade de formação, a prática/reflexiva, por meio do trabalho colaborativo de investigação-ação, de abordagem interdisciplinar, tanto na formação, do diálogo entre as áreas, como na busca de integrar/ abordar os conhecimentos escolares no ensino e na aprendizagem;

- Experiências relacionais entre os bolsistas e o público-alvo da educação especial, a partir de seus contextos e especificidades;

- Uma formação teórica/prática sobre a educação inclusiva, a partir da aproximação da realidade e atividade teórica de pesquisa;

- Reflexões sobre as ações e as contradições da prática no contexto escolar; 
- Aprofundar estudos em educação inclusiva em Trabalhos de Conclusão de Curso (TCC);

- Um fazer docente baseado na escuta sensível para uma educação mais humanizadora;

- A tomada de consciência para a docência como prática social inclusiva;

- A formação de bolsistas "multiplicadores", nas salas de aula da universidade, quando traziam a temática da educação inclusiva e experiências do Pibid para os trabalhos solicitados pelos professores dos respectivos cursos, aspecto observado nos relatos proferidos pelos próprios bolsistas;

- Aos professores da academia e aos ID, repensar os projetos acadêmicos curriculares nos cursos de formação inicial no que tange à educação inclusiva, a partir da interlocução com a educação básica.

Enfim, a interação da Matemática com outras áreas de conhecimento que envolvem o planejamento e enfrentamento da realidade no contexto inclusivo, configurou-se como uma ação possível e inovadora, na formação para a educação inclusiva, cujos desafios são imensos.

Nessa oportunidade, o subprojeto configurou-se como uma importante ação das políticas públicas em nosso país, para instrumentalizar e materializar propostas e projetos pedagógicos por meio de uma perspectiva crítica e reflexiva, na construção de conhecimentos formativos e de aportes práticos, redimensionando nossas posturas, ações e atitudes para uma educação que acolhe a diferença e compreende as possibilidades de aprendizagens entre educadores e pessoas com deficiência, em busca de processos educativos mais inclusivos e humanizados.

\section{REFERÊNCIAS}

BRASIL. Constituição da República Federativa do Brasil. Brasília, DF: Senado Federal: Centro Gráfico, 1988. 
BRASIL. Lei no 9.394, de 20 de dezembro de 1996. Estabelece as diretrizes e bases da educação nacional. Brasília, DF, 1996. Disponível em: http://www.planalto.gov.br/ccivil_03 / leis/L9394.htm. Acesso em: 23 abr. 2018.

BRASIL. Conselho Nacional de Educação. Parecer no 17/2001, de 3 de julho de 2001. Diretrizes nacionais para a educação especial na educação básica. Brasília, DF: Conselho Nacional de Educação, 2001.

BRASIL. Política nacional de educação especial na perspectiva da educação inclusiva. Brasília, DF: MEC/SEESP, 2008. Disponível em: http://portal.mec.gov.br/arquivos/pdf/ politicaeducespecial.pdf. Acesso em: 12 jun. 2018.

BRASIL. Resolução no 4, de 13 de julho de 2010. Define diretrizes curriculares nacionais gerais para a educação básica. Disponível em: http://portal.mec.gov.br/dmdocuments/ rceb004_10.pdf. Acesso em: 25 abr. 2018.

BRASIL. Decreto № 7.219, de 24 de junho de 2010. Dispõe sobre o Programa Institucional de Bolsa de Iniciação à Docência - Pibid e dá outras providências. Disponível em: http:// www.planalto.gov.br/ccivil_03/_ato2007-2010/2010/decreto/d7219.htm. Acesso em: 13 jun. 2018.

BRASIL. Presidência da República. Casa Civil. Subchefia para Assuntos Jurídicos. Decreto 7.611, de 17 de novembro de 2011. Revoga o Decreto no 6.571, de 17 de setembro de 2008. Dispõe sobre a educação especial, o atendimento educacional especializado e dá outras providências. Brasília, DF, 2011.

BRASIL. Lei no 12.796, de 4 de abril de 2013. Altera a Lei no 9.394, de 20 de dezembro de 1996. Estabelece as diretrizes e bases da educação nacional, para dispor sobre a formação dos profissionais da educação e dar outras providências. Disponível em: http:// www.planalto.gov.br/ccivil_03/_ato2011-2014/2013/lei//12796.htm. Acesso em: 22 set. 2018.

BRASIL. Portaria no 096, de 18 de julho de 2013. Regulamenta as normas do Programa Institucional de Bolsa de Iniciação à Docência. Disponível em: https://www.capes.gov.br/ images/stories/download/legislacao/Portaria_096_18jul13_AprovaRegulamentoPIBID.pdf. Acesso em: 11 abr. 2018.

BRASIL. Presidência da República. Casa Civil. Lei no 13.005, de 25 de junho de 2014. Aprova o Plano Nacional de Educação - PNE - e dá outras providências, 2014.

BRASIL. Conselho Nacional de Educação. Define as Diretrizes Curriculares Nacionais para a formação inicial em nível superior (cursos de licenciatura, cursos de formação pedagógica para graduados e cursos de segunda licenciatura) e para a formação continuada. Resolução CNE/CP no 02/2015, de 1o de julho de 2015. Brasília, Diário Oficial [da] República Federativa do Brasil, seção 1, n. 124, p. 8-12, 2 jul. 2015.

BRASIL. Lei no 13.146, de 6 de julho de 2015. Institui a Lei Brasileira de Inclusão da Pessoa com Deficiência (Estatuto da Pessoa com Deficiência). Brasília, DF, Brasil. Disponível em: http://www.planalto.gov.br/ccivil_03/_Ato2015-2018/2015/Lei/L13146.htm. Acesso em: 10 jul. 2018.

CAST. Universal design for learning guidelines, version 2.0. Wakefield, MA, 2011. Disponível em: http://www.udlcenter.org/aboutudl/udlguidelines/downloads. Acesso em: 14 jun. 2019. 
DAMÁZIO, M. F. M. Atendimento educacional especializado: pessoa com surdez. São Paulo: MEC/SEESP, 2007. Disponível em: http://portal.mec.gov.br/seesp/arquivo s/ pdf/ aee_da.pdf. Acesso em: 23 ago. 2013.

DENARI, F. E.; SIGOLO, S. R. R. L. Formação de professores em direção à educação inclusiva no Brasil: dilemas atuais. In: POKER, R. B.; MARTINS, S. E. S. DE O.; GIROTO, C. R. M. (org.). Educação inclusiva: em foco a formação professores. São Paulo: Cultura Acadêmica, 2016, cap. 1, p. 15-31.

DOURADO, L. F. Diretrizes curriculares nacionais para a formação inicial e continuada dos profissionais do magistério da educação básica: concepções e desafios. Educação e Sociedade, Campinas, v. 36, n. 131, 2015.

DUK, C. Educar na diversidade: material de formação docente. Brasília: MEC, SEESP, 2006. Disponível em: http://portal.mec.gov.br/seesp/arquivos/pdf/ educarnadiversidade2006.pdf. Acesso em: 10 jun. 2018.

ESPINOSA, A. J; FIORENTINI, D. (Re)significação e reciprocidade de saberes e práticas no encontro de professores de matemática da escola e da universidade, 2005. In: FIORENTINI, D.; NACARATO, A. M. (org.). Cultura, formação e desenvolvimento profissional de professores que ensinam matemática: investigando e teorizando a partir de prática. São Paulo: Musa Editora, 2005. p. 152-174.

GLAT, R.; PLETSCH, M. D. O papel da Universidade no contexto da política de educação inclusiva: reflexões sobre a formação de recursos humanos e a produção de conhecimento. Revista de Educação Especial, v. 23, n. 38, 2010. Disponível em: https:// periodicos.ufsm.br/educacaoespecial/article /viewFile/2095/1444. Acesso em: 13 fev. 2018.

MACHADO, M. I. P. C. Cooperar para aprender: um estudo de investigação-ação no ensino-aprendizagem da gramática portuguesa. Lisboa, 2014. 324f. Tese (Doutorado de Ciências Sociais, Educação e Administração) - Universidade Lusófona de Humanidades e Tecnologias de Lisboa, 2014.

MARTINS, L. DE A. R. Reflexões sobre a formação de professores com vistas à educação inclusiva. In: MIRANDA, T. G.; FILHO, T. A. G. (org.). O professor e a educação inclusiva: formação, práticas e lugares. Salvador: EDUFBA, 2012. p. 25-38.

MOREIRA, P. C.; DAVID, M. M. M. S. O conhecimento matemático do professor. Revista Brasileira de Educação, n. 28, 2005. Disponível em: http://www.scielo.br/scielo.php? pid $=$ S1413-24782005000100005\&script $=$ sci

abstract\&tlng=pt. Acesso em: 25 abr. 2018.

MOURA, M. O. Controle da variação de quantidades: atividades de ensino. São Paulo: FE-USP, 1996.

MOURA, M.O. A atividade de ensino como ação formadora. In: CASTRO, A. D.; CARVALHO, A. M. P. (org.). Ensinar a ensinar. São Paulo: Pioneira, 2001. p.143-162.

MOURA, M. O; ARAÚJO, E. S.; SOUZA, F. D.; PANOSSIAN, M. L.; MORETTI, V. D. A Atividade orientadora de ensino como unidade entre ensino e aprendizagem. In: MOURA, M. O. (org.). A atividade pedagógica na teoria histórico-cultural. São Paulo: Autores Associados, 2016. p. 93-125. 
MUNIZ, S. C. S. A inclusão de surdos nas aulas de Matemática: uma análise das relações pedagógicas envolvidas na tríade professora-intérprete-surdo. Ilhéus, BA, 2018. 116f. Dissertação (Mestrado em Educação Matemática) - Universidade Estadual de Santa Cruz (Uesc), 2018.

NASCIMENTO, E. DE S.; CORREIA, P. C. DA H.; PORTELA, C. P. DE J. Dialongando com a inclusão II: curso de formação de professores. Recife: Editora Liceu, 2014.

NUNES, C.; MADUREIRA, I. Desenho universal para a aprendizagem: construindo práticas pedagógicas inclusivas. Da investigação às práticas, v. 5, n. 2, 2015.

ORGANIZAÇÃO DAS NAÇÕES UNIDAS (ONU). Convenção sobre os direitos das pessoas com deficiência. 2006. Doc. A/61/611. Nova York.

ORGANIZAÇÃO DAS NAÇÕES UNIDAS PARA A EDUCAÇÃO, A CIÊNCIA E A CULTURA (UNESCO). Declaração mundial sobre educação para todos: plano de ação satisfazer as necessidades básicas de aprendizagem. Unesco: Jomtien. 1990.

ORGANIZAÇÃO DAS NAÇÕES UNIDAS PARA A EDUCAÇÃO, A CIÊNCIA E A CULTURA (UNESCO). 48TH INTERNATIONAL CONFERENCE ON EDUCATION - Conclusions and Recommendations. Geneve: IBE, 2008.

RODRIGUES, D.; LIMA-RODRIGUES, L. Formação de professores e inclusão: como se reformam os reformadores. Educar em Revista, Curitiba, 2011. Disponível em: http:// www.scielo.br/pdf/er/n41/04.pdf. Acesso em: 14 jun. 2018.

ROSE, D.; MEYER, A. Teaching every student in the digital age. Alexandria, VA: ASCD. 2002. Disponível em: http://www.cast.org/teachingeverystudent/ideas/tes/. Acesso em: jun. 2017.

SANTOS, M. X. A formação em serviço no PNAIC de professores que ensinam matemática e construções de práxis pedagógicas. Brasília, DF, 2017. 135f. Dissertação (Mestrado em Educação) - Universidade de Brasília (UnB), 2017.

SKLIAR, C. Pedagogia (improvável) da diferença: e se outro não estivesse aí? Rio de Janeiro: DP\&A, 2003.

SOUZA, E. J. Sobre a história dos números. Disponível em: http://www.ifba.edu.br/dca/ corpo_docente/mat/ejs/sobre_a_historia_dos_numeros.pdf. Acesso em: 11 nov. 2018. 